\title{
Re-treatment rates after treatment with the Pipeline Embolization Device alone versus Pipeline and coil embolization of cerebral aneurysms: a single-center experience
}

\author{
Min S. Park, MD, ${ }^{1}$ Michael Nanaszko, MD, ${ }^{2}$ Matthew R. Sanborn, MD, ${ }^{2}$ Karam Moon, MD, ${ }^{2}$ \\ Felipe C. Albuquerque, MD, ${ }^{2}$ and Cameron G. McDougall, MD, FRCSC ${ }^{2}$
}

'Department of Neurosurgery, University of Utah Health Care, Salt Lake City, Utah; and 'Department of Neurosurgery, Barrow Neurological Institute, St. Joseph's Hospital and Medical Center, Phoenix, Arizona

\begin{abstract}
OBJECTIVE The optimal strategy for use of the Pipeline Embolization Device (PED, ev3 Neurovascular) has not been clearly defined. The authors examined re-treatment rates after treatment with PED alone versus PED and adjunctive coil embolization (PED/coil).
\end{abstract}

METHODS The authors retrospectively examined cerebral aneurysms treated with the PED from May 2011 to March 2014. Overall, 133 patients ( 25 men, 108 women; mean age 60.4 years, range 23-85 years) were treated for 140 aneurysms (mean size $11.8 \pm 8.3 \mathrm{~mm}$ ) requiring 224 PEDs (mean 1.7 PEDs per patient). Sixty-eight patients (13 men, 55 women) were treated with PED alone for 73 aneurysms (mean size $10.6 \pm 9.2 \mathrm{~mm}$ ) and 65 patients (12 men, 53 women) were treated with PED/coil for 67 aneurysms (mean size $12.8 \pm 7.4 \mathrm{~mm}$ ).

RESULTS Eight aneurysms in 8 patients were re-treated in the PED-alone cohort versus only 1 aneurysm in 1 patient in the PED/coil cohort for re-treatment rates of $11.8 \%(8 / 68)$ and $1.5 \%(1 / 65)$, respectively $(p=0.03)$. Two patients in the PED-alone cohort were re-treated due to PED contraction, while the other 6 were re-treated for persistent filling of the aneurysms. The PED/coil patient experienced continued filling of a vertebrobasilar artery aneurysm. No aneurysms in either group ruptured after treatment.

CONCLUSIONS Adjunctive coil embolization during flow diversion with the PED resulted in a significantly lower retreatment rate compared with PED alone, suggesting an added benefit with adjunctive coil embolization. This result may provide the basis for future evaluation with randomized, controlled trials.

http://thejns.org/doi/abs/10.3171/2015.7.JNS15582

KEY WORDS aneurysms; coil embolization; flow diversion; Pipeline Embolization Device; re-treatment; vascular disorders

$\mathrm{T}$ HE Pipeline Embolization Device (PED, ev3 Neurovascular) has become a valuable tool in the armamentarium of the neuro-interventional surgeon. Since the US Food and Drug Administration (FDA) approved flow-diverting stents in 2011, their use has become commonplace at many institutions in the United States and around the world. A plethora of reports and series in the medical literature have been published illustrating this wide-scale adoption. $17,10,11,14,15,17,18,22,24$

Aneurysms that were previously considered "uncoil- able" are now being routinely treated with the PED and other flow-diverting stents. However, the optimal strategy for the use of this new technology has not been examined in great detail. Although flow-diverting stents are designed as stand-alone constructs, many practitioners augment the construct with concurrent coil embolization of the aneurysm. ${ }^{10,15,18,22}$

To better understand this issue, we reviewed our experience with the use of the PED as a stand-alone construct versus its use with adjunctive coil embolization in the 
reconstructive treatment of cerebral aneurysms. Specifically, we examined the re-treatment rates with a strategy of PED alone versus with adjunctive coil embolization.

\section{Methods}

Approval for this project was obtained from the institutional review board of St. Joseph's Hospital and Medical Center, Phoenix, Arizona. Additional analyses relating to this same patient group have been previously published. ${ }^{19}$

We performed a retrospective review of a prospectively maintained endovascular database of consecutive cases performed at our institution with the PED after FDA approval in April 2011. The inpatient and outpatient medical records and all relevant imaging studies were examined to identify key demographic information (patient age and sex) and numbers, locations, and sizes of the cerebral aneurysms treated. Additionally, we recorded the number of devices used during the procedure, whether adjunctive coil embolization was performed simultaneously, and all follow-up imaging data. In the event of a re-treatment, we analyzed the time to re-treatment and the reason for the re-treatment. All measurements and assessments were performed by the authors.

Our procedure for treatment of cerebral aneurysms with the PED has been previously described. ${ }^{19}$ During adjunctive coil embolization, the aneurysm was either coiled by a jailed microcatheter after PED deployment or initially coiled with balloon remodeling immediately followed by deployment of the PED. Coil embolization was performed to promote earlier thrombosis of the aneurysm, and no attempt was made to perform complete occlusion of the aneurysm with coils.

Patients lost to follow-up were considered to not require re-treatment of their aneurysms. This decision reflects the real-life practice environment where identification of aneurysm residuals or recurrence cannot occur without a patient willing to return for follow-up studies. Certainly, there will be a small subset of these patients who may harbor residual or recurrent aneurysms and may potentially be candidates for re-treatment.

Frequencies and descriptive statistics, including counts, percentages, means, and standard deviations, are presented. The mean differences between continuous variables were analyzed using independent-samples t-tests and chisquare tests or Fisher exact tests to test for an association between categorical variables; $p$ values less than 0.05 were considered significant. SPSS version 21 was used for statistical analyses.

\section{Results \\ Patient Characteristics}

The PED was used to treat 133 patients for 140 cerebral aneurysms between May 2011 and March 2014 by the senior authors (F.C.A., C.G.M.) (Table 1). The patients' mean age at initial PED treatment was 60.4 years (SD 14.0 years, range $23-85$ years). The group included 108 women $(81.2 \%)$ and 25 men $(18.8 \%)$.

Of the 140 aneurysms treated, $121(86.4 \%)$ were located in the anterior circulation and 19 (13.6\%) were located in the posterior circulation. The mean size of the aneu- rysms was $11.8 \mathrm{~mm}$ (SD $8.3 \mathrm{~mm}$ ). The mean number of PEDs required per procedure was 1.7 (SD 1.2). Average length of follow-up was 9.3 months (SD 5.6 months). Retreatments were performed only in those patients with aneurysms that had persistent filling at the time of follow-up. Overall, there was a statistically significant difference between the 2 cohorts with respect to the number of patients who underwent aneurysm re-treatment: $8(11.8 \%)$ of 68 of those originally treated with PED alone and $1(1.5 \%)$ of 65 patients in the PED/coil cohort ( $\mathrm{p}=0.03$, Fisher exact test).

Of the 133 patients studied, $68(51.1 \%)$ were treated with PED as a stand-alone construct and 65 (48.9\%) had simultaneous adjunctive coil embolization (Table 1). The 2 cohorts were otherwise well matched, with a non-statistically significant difference in aneurysm size $(p=0.13$, independent-samples t-test). There was no difference in the timing of treatment strategies, which were equally employed throughout the study period. However, there was a statistically significant difference $(p=0.01$, Fisher exact test) in treatment performed based on vessel location, with substantially more aneurysms in the posterior circulation treated with PED alone $(15 / 73,20.5 \%)$ than with PED and coil embolization $(4 / 67,6.0 \%)$.

\section{PED-Alone Cohort}

Eight (11.7\%) of the 68 patients treated with PED alone went on to have a subsequent re-treatment at a mean time of 6.5 months (SD 3.8 months) after their initial treatment (Table 2). Two patients were re-treated because of PED migration/retraction resulting in uncovering of the aneurysm neck (Fig. 1). The other 6 patients were re-treated due to persistence of aneurysm filling at the time of follow-up angiography (Table 3). Five of these 6 patients were retreated with placement of additional devices.

In 1 case, persistent filling of a large cavernous internal carotid artery (ICA) aneurysm with a proximal endoleak, despite attempts at balloon angioplasty during the initial treatment, was treated by navigating a microcatheter around the proximal PED into the aneurysm followed by coil embolization and additional PED placement (Fig. 2). Another individual with a recurrence after clip ligation of a posterior communicating artery aneurysm had significant luminal narrowing of the ophthalmic segment of the ICA, which was exacerbated by catheter-induced vasospasm during navigation of the microcatheter and deployment of the PED. The procedure was also complicated by acute thrombus formation and occlusion of the anterior cerebral artery, requiring thrombolysis. Due to the inherent vessel anatomy and technical complications, the PED was deployed with inadequate coverage of the aneurysm neck. The patient was stabilized following the procedure and returned the following day for placement of an additional device.

In the PED-alone cohort, there was a statistically significant difference ( $\mathrm{p}=0.03$, independent-samples t-test) in mean aneurysm size for those patients requiring retreatment (mean 17.1, SD $12.6 \mathrm{~mm}$ ) versus those not requiring re-treatment (mean $9.8 \mathrm{~mm}, \mathrm{SD} 8.4 \mathrm{~mm}$ ). Patients requiring re-treatment also required, on average, significantly more PEDs in their treatment $(\mathrm{p}=0.001$, independent-samples t-test). No statistically significant difference 
TABLE 1. Summary of clinical and demographic characteristics of patients in this study*

\begin{tabular}{lllll}
\hline \multicolumn{1}{c}{ Characteristic } & All Patients & PED Alone & PED/Coil & p Value \\
\hline No. of patients & 133 & 68 & 65 \\
\hline Age in yrs, mean (SD) & $60.4(14.0)$ & $59.4(14.6)$ & $61.4(13.4)$ \\
\hline Sex & & & & \\
\hline Male & $25(18.8 \%)$ & $13(19.1 \%)$ & $12(18.4 \%)$ \\
\hline Female & $108(81.2 \%)$ & $55(80.9 \%)$ & $53(81.5 \%)$ \\
\hline No. of aneurysms treated & 140 & 73 & 67 & \\
\hline Aneurysm size in mm, mean (SD) & $11.8(8.3)$ & $10.6(9.2)$ & $12.8(7.4)$ & 0.13 \\
\hline Vessel location & & & & \\
\hline Anterior & $121(86.4 \%)$ & $58(79.5 \%)$ & $63(94.0 \%)$ & \\
\hline Posterior & $19(13.6 \%)$ & $15(20.5 \%)$ & $4(6.0 \%)$ & 0.01 \\
\hline No. of PEDs, mean (SD) & $1.7(1.2)$ & $1.9(1.4)$ & $1.5(0.8)$ & \\
\hline Follow-up in mos, mean (SD) & $9.3(5.6)$ & $9.6(5.6)$ & $9.0(5.6)$ & \\
\hline
\end{tabular}

* Total numbers and percentage of cohort are presented unless otherwise stated. The PED/coil cohort was treated with PED and adjunctive coil embolization.

in vessel location was identified for re-treated aneurysms $(\mathrm{p}=0.19$, Fisher exact test $)$.

\section{PED/Coil Cohort}

Of the 65 patients treated with PED and adjunctive coil embolization in our series, only 1 required re-treatment (Table 4). This individual had a $22-\mathrm{mm}$ aneurysm involving the basilar trunk and underwent initial treatment with partial coil embolization and deployment of 6 telescoping PEDs (Fig. 3). The 3-month follow-up angiogram revealed a persistent endoleak into the aneurysm, which was unchanged at the 10-month follow-up study. At that time, 2 additional PEDs were placed over the neck of the aneurysm.

\section{Complications}

We did not identify any difference in the rate of major neurological and technical complications between the 2 cohorts $(2.9 \%$ permanent and $25.0 \%$ total in the PED-alone cohort vs $3.1 \%$ permanent and $24.6 \%$ total complications in the PED/coil cohort) (Table 5). Thirty-three patients experienced complications as a result of treatment with the PED, as we have previously reported..$^{19}$ In the PED-alone cohort, 17 (25\%) of the 68 patients experienced complications, which resulted in permanent morbidity and/or mortality in only 2 cases $(2.9 \%)$. The other 15 patients $(22.1 \%$ of the PED-alone cohort) made full recoveries.

A total of 16 individuals (24.6\%) had complications in the PED/coil cohort. Only 2 (3.1\%) of the patients experienced permanent morbidity and/or mortality resulting from their procedures. The remaining 14 patients $(21.5 \%$ of the PED/coil cohort) made full recoveries from their complications.

\section{Discussion}

The optimal strategy for use of the PED has not been

TABLE 2. Demographic and clinical characteristics of the cohort treated with PED alone stratified by need for re-treatment*

\begin{tabular}{|c|c|c|c|c|}
\hline Characteristic & PED Alone & No $\operatorname{Re}-T x$ & Re-Tx & $\mathrm{p}$ Value \\
\hline No. of patients & 68 & 60 & 8 & \\
\hline Age in yrs, mean (SD) & $59.4(14.6)$ & $59.7(14.5)$ & $57.3(16.4)$ & \\
\hline \multicolumn{5}{|l|}{ Sex } \\
\hline Male & $13(19.1 \%)$ & $12(20.0 \%)$ & $1(12.5 \%)$ & \\
\hline Female & $55(80.9 \%)$ & $48(80.0 \%)$ & $7(87.5 \%)$ & \\
\hline No. of aneurysms treated & 73 & 65 & 8 & \\
\hline Aneurysm size in mm, mean (SD) & $10.6(9.2)$ & $9.8(8.4)$ & $17.1(12.6)$ & 0.03 \\
\hline Vessel location & & & & 0.19 \\
\hline Anterior & $58(79.5 \%)$ & $50(76.9 \%)$ & $8(100 \%)$ & \\
\hline Posterior & $15(20.5 \%)$ & $15(23.1 \%)$ & 0 & \\
\hline No. of initial PEDs, mean (SD) & $1.9(1.4)$ & $1.65(0.8)$ & $3.4(3.3)$ & 0.001 \\
\hline Time to re-Tx in mos, mean (SD) & & - & $6.5(3.8)$ & \\
\hline Follow-up in mos, mean (SD) & $9.6(5.6)$ & $9.8(5.9)$ & $8.6(3.8)$ & \\
\hline
\end{tabular}



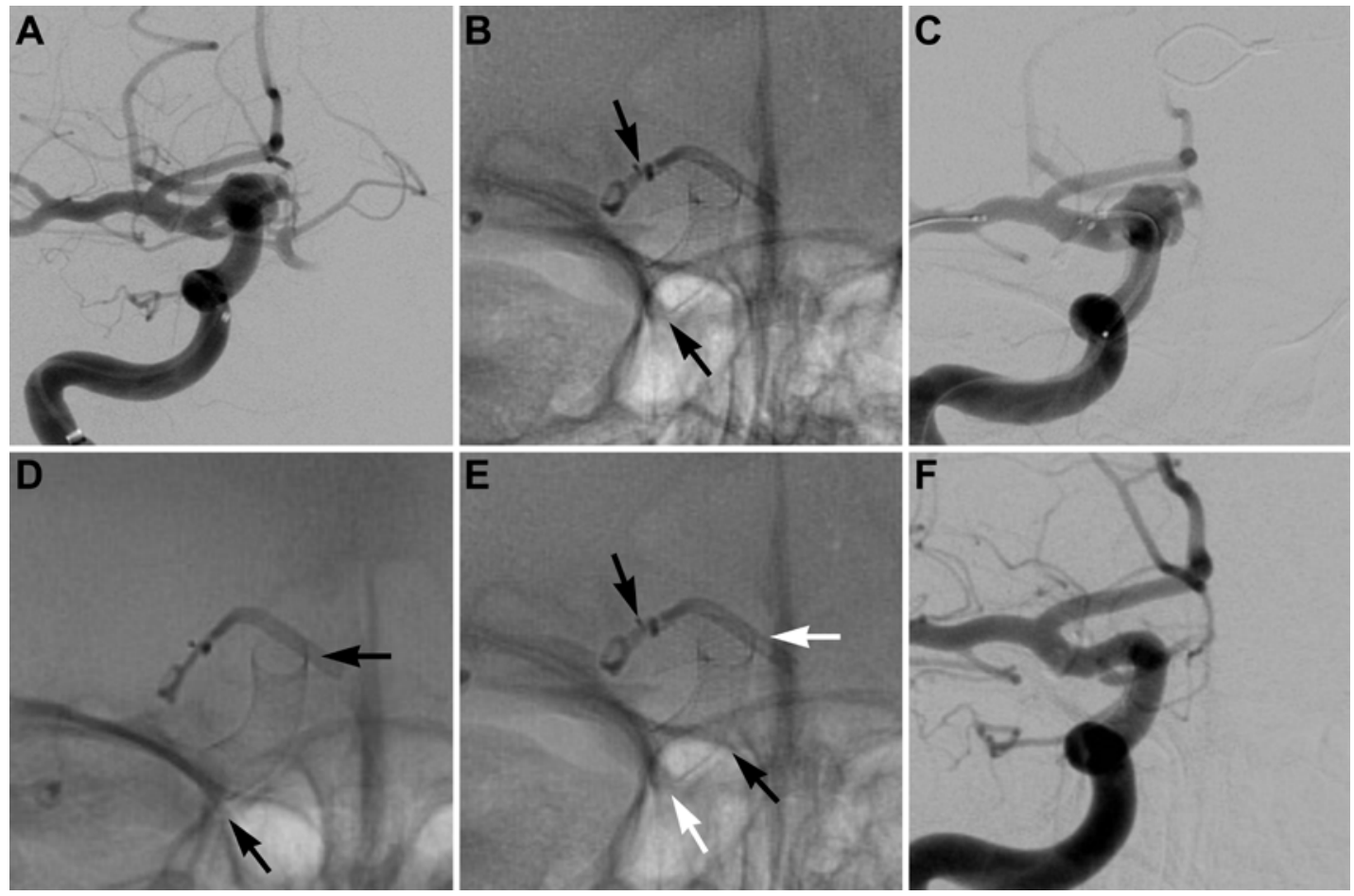

FIG. 1. Re-treatment Case 1, illustrating PED retraction. A: Right ICA injection after PED deployment demonstrating a supraclinoid ICA aneurysm recurrence after clipping. B: Native projection after PED deployment. Note the position of the proximal and distal aspects of the PED (black arrows) in relation to the aneurysm clip. C: Six-month follow-up angiogram demonstrating continued filling of the aneurysm. D: Native projection demonstrating contraction of the distal PED exposing the aneurysm neck. The black arrows indicate the proximal and distal aspects of the PED after retraction. E: Native projection after deployment of second telescoping PED (black arrows). Note the position of the first PED (white arrows), which has retracted, uncovering the aneurysm. F: Nine-month follow-up angiogram demonstrating complete occlusion of aneurysm.

clearly determined., ${ }^{3,5,20}$ Although the PED is designed for use as a stand-alone construct, many practitioners have added coil embolization to the procedure in the hope of promoting earlier occlusion and avoiding the small risk of delayed aneurysmal hemorrhage. Indeed, the first report of use of the PED in North America, by Fiorella et al., involved a large, fusiform vertebral artery aneurysm that was treated with overlapping PEDs and partial coil embolization. ${ }^{10}$ The surgeons initially jailed a microcatheter into the aneurysm and proceeded with PED deployment. Although there was marked decrease in aneurysm filling, they elected to proceed with coil embolization in the hope of improving the aneurysm occlusion. The aneurysm progressed to complete occlusion within 72 hours, and the patient was reportedly doing well 1 year after treatment. In our series, we found a statistically significant difference in the need for re-treatment of aneurysms treated with a strategy of PED alone versus with adjunctive coil embolization.

Chalouhi et al. advocate using a single PED as the initial treatment of most aneurysms, whenever feasible. ${ }^{5}$ They identified a statistically significant increase in the rate of

TABLE 3. Clinical and demographic characteristics of patients who underwent re-treatment

\begin{tabular}{ccclcccl}
\hline $\begin{array}{c}\text { Case } \\
\text { No. }\end{array}$ & Age $(\mathrm{yrs})$ & Sex & Aneurysm Location & $\begin{array}{c}\text { Aneurysm } \\
\text { Size }(\mathrm{mm})\end{array}$ & Tx & $\begin{array}{c}\text { No. of } \\
\text { PEDs }\end{array}$ & Reason for Re-Tx \\
\hline 1 & 61 & F & PCoA & 8.5 & PED alone & 1 & PED migration/retraction \\
\hline 2 & 47 & F & Cavernous ICA & 31 & PED alone & 2 & Residual \\
\hline 3 & 60 & F & Cavernous ICA & 15 & PED alone & 2 & Residual \\
\hline 4 & 28 & M & Cavernous ICA & 40 & PED alone & 11 & Residual \\
\hline 5 & 83 & F & Cavernous ICA & 20 & PED alone & 4 & Residual \\
\hline 6 & 67 & F & Cavernous ICA & 12 & PED alone & 4 & Residual \\
\hline 7 & 64 & F & PCoA & 7.6 & PED alone & 2 & PED migration/retraction \\
\hline 8 & 48 & F & PCoA & 3 & PED alone & 1 & Inadequate neck coverage \\
\hline 9 & 32 & F & Basilar & 22 & PED/coil & 6 & Residual \\
\hline
\end{tabular}

$\mathrm{PCOA}=$ posterior communicating artery. 

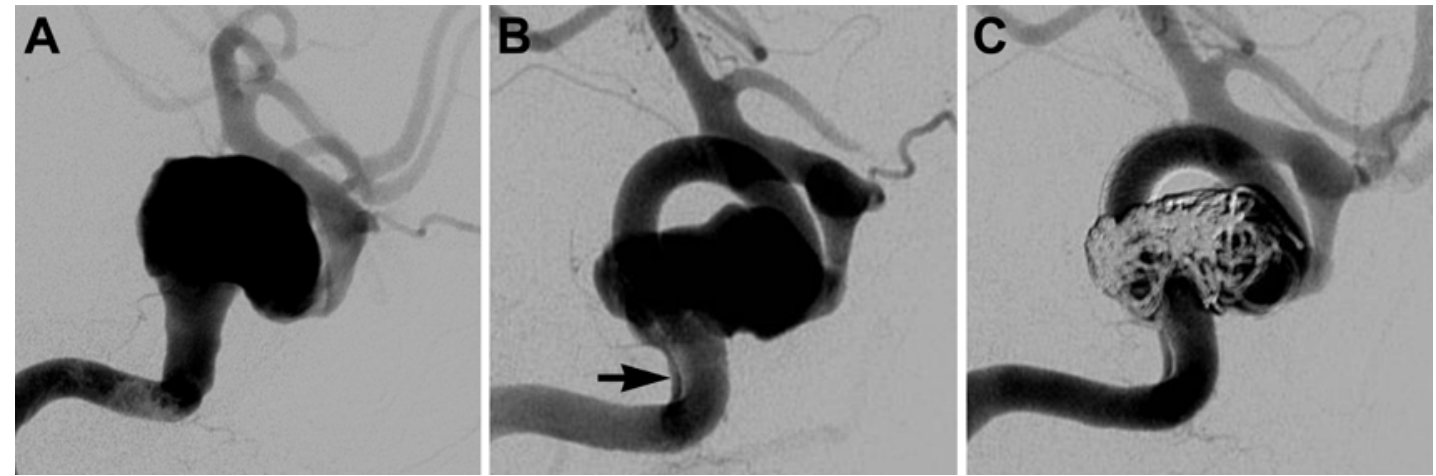

FIG. 2. Case 2, illustrating continued filling of a cavernous ICA aneurysm treated with PED alone requiring re-treatment. A: Left ICA injection of a 20-mm cavernous ICA aneurysm before treatment. B: Seven-month follow-up angiogram demonstrating significant remodeling after treatment with overlapping PEDs, but continued filling of the aneurysm. Note the proximal endoleak despite balloon angioplasty at the time of the initial placement (black arrow). C: Final angiogram obtained after coil embolization and additional PED placement.

complications with lower long-term occlusion rates when multiple devices were employed. They performed adjunctive coil embolization in cases in which both single and multiple PED were used but did not identify any differences in these treatments in their statistical analysis. We have previously published our complication rate with the use of the PED at the Barrow Neurological Institute. ${ }^{19}$

\section{Deciding on PED Treatment Strategy}

The decision to proceed with concurrent coil embolization is at the discretion of the practitioner, if there are concerns about the extent of flow modification with the PED. The initial results after deployment can demonstrate significant change in the flow dynamics of the aneurysm, with delayed filling and contrast stasis. Also, while complete occlusion is more often a delayed phenomenon, some believe that the addition of coils to the aneurysm may pro-

TABLE 4. Demographic and clinical characteristics of the PED/ coil cohort stratified by need for re-treatment*

\begin{tabular}{llll}
\hline \multicolumn{1}{c}{ Characteristic } & PED/Coil & No Re-Tx & Re-Tx \\
\hline No. of patients & 65 & 64 & 1 \\
\hline Age in yrs, mean (SD) & $61.4(13.4)$ & $61.9(12.9)$ & 32 \\
\hline Sex & & & \\
\hline Male & $12(18.5 \%)$ & $12(18.8 \%)$ & 0 \\
\hline Female & $53(81.5 \%)$ & $52(81.2 \%)$ & $1(100 \%)$ \\
\hline No. of aneurysms treated & 67 & 66 & 1 \\
\hline Aneurysm size in mm, mean & $12.8(7.4)$ & $12.7(7.0)$ & 22 \\
$\quad$ (SD) & & & \\
\hline $\begin{array}{l}\text { Vessel location } \\
\text { Anterior }\end{array}$ & $63(94.0 \%)$ & $63(95.5 \%)$ & 0 \\
\hline Posterior & $4(6.0 \%)$ & $3(4.5 \%)$ & $1(100 \%)$ \\
\hline No. of initial PEDs, mean (SD) & $1.5(0.8)$ & $1.4(0.6)$ & 6 \\
\hline $\begin{array}{l}\text { Time to re-Tx in mos, mean } \\
\text { (SD) }\end{array}$ & & - & 10 \\
\hline Follow-up in mos, mean (SD) & & $8.9(5.7)$ & 10 \\
\hline
\end{tabular}

* Total numbers and percentage of cohort are presented unless otherwise stated. mote faster occlusion. Given the reports of catastrophic delayed aneurysm rupture after the use of flow-diverting stents, $5,12,13,20,21,23$ the desire to promote earlier aneurysm occlusion is understandable.

Likewise, our decision to proceed with PED alone versus PED and coil placement mirrored these beliefs. In instances where a microcatheter was jailed within the aneurysm during PED deployment, the decision to proceed with adjunctive coil embolization was determined by the senior authors' judgment concerning the extent of flow modification and contrast stasis within the aneurysm.

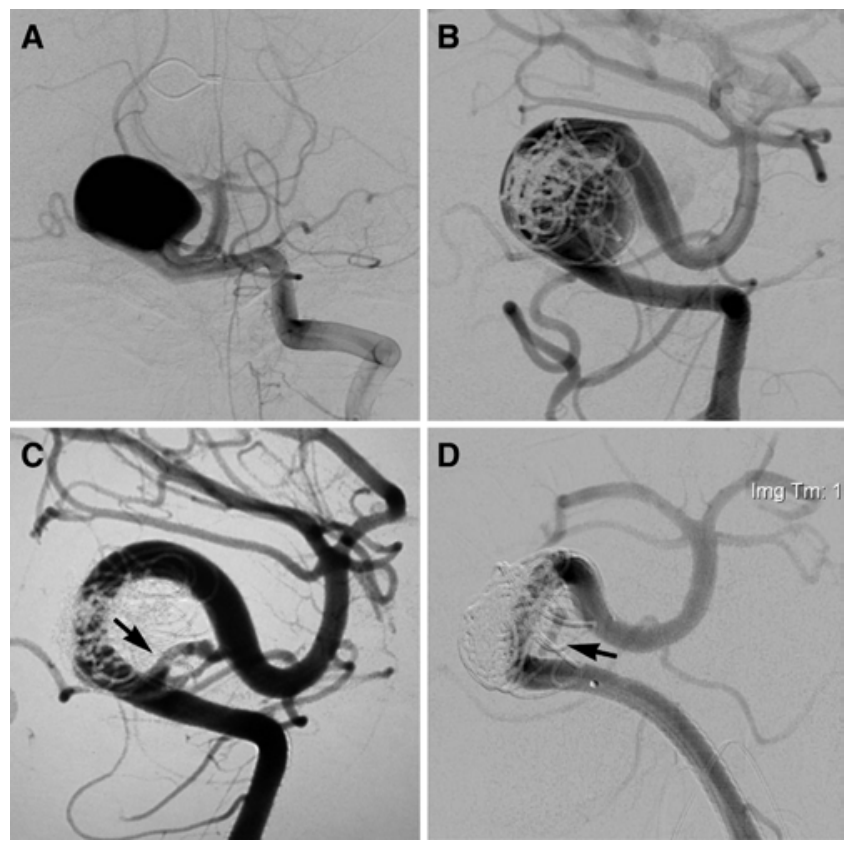

FIG. 3. Case 3, illustrating a large vertebral artery aneurysm treated with $\mathrm{PED} /$ coil requiring re-treatment. A: Left vertebral artery injection demonstrating a 22-mm proximal basilar artery aneurysm before treatment. B: Immediate posttreatment angiogram demonstrating significant flow modification after PED and coil placement. C: Follow-up angiogram demonstrating continued endoleak at the proximal in-flow zone (black arrow). D: Final angiogram obtained after placement of 2 additional PEDs with contrast stasis within the aneurysm (black arrow). 
TABLE 5. Characteristics of patients who underwent re-treatment in the 2 cohorts*

\begin{tabular}{|c|c|c|c|}
\hline Characteristic & PED Alone & PED/coil & $\begin{array}{c}p \\
\text { Value }\end{array}$ \\
\hline No. of patients & $8 / 68(11.7 \%)$ & $1 / 65(1.5 \%)$ & 0.03 \\
\hline Age in yrs, mean (SD) & $57.3(16.4)$ & 32 & \\
\hline \multicolumn{4}{|l|}{ Sex } \\
\hline Male & 1 & 0 & \\
\hline Female & 7 & 1 & \\
\hline No. of aneurysms treated & 8 & 1 & \\
\hline Aneurysm size in mm, mean (SD) & $17.1(12.6)$ & 22 & \\
\hline \multicolumn{4}{|l|}{ Vessel location } \\
\hline Anterior & 8 & 0 & \\
\hline Posterior & 0 & 1 & \\
\hline No. of PEDs, mean (SD) & $3.4(3.3)$ & 6 & \\
\hline Time to re-Tx in mos, mean (SD) & $6.5(3.8)$ & 10 & \\
\hline Follow-up in mos, mean (SD) & $8.6(3.8)$ & 10 & \\
\hline \multicolumn{4}{|l|}{ Complications } \\
\hline Total & $17(25.0 \%)$ & $16(24.6 \%)$ & \\
\hline Permanent & $2(2.9 \%)$ & $2(3.1 \%)$ & \\
\hline
\end{tabular}

* Total numbers and percentage of cohort are presented unless otherwise stated.

Aneurysms that were coiled prior to PED deployment reflected our changing practice of not jailing microcatheters during deployment of the flow-diverting stent. In these instances, the determination to use adjunctive coil embolization was made before beginning the procedure. Our strategy for adjunctive coil embolization respected previous reports of catastrophic device occlusion from dense packing of the aneurysm, as reported by Siddiqui et al. ${ }^{21}$ Thus, we performed packing of the aneurysm primarily to augment the disruption of the inflow jet, an end point that could often be achieved with comparatively loose packing. Depending on the anatomy of the aneurysm, coiling prior to PED placement has the potential to limit visibility during PED placement if the coiling is dense.

Although deciding on which treatment strategy to employ is subjective by nature, this did not result in a statistically significant difference in aneurysm size between the 2 cohorts.

In the Pipeline Embolization Device for Intracranial Aneurysms trial, Nelson et al. treated 16 of 31 patients with PED and coil embolization. ${ }^{18}$ They reported an excellent occlusion rate of $93 \%$ (occlusion observed in 28 of 30 patients) at 6 months after treatment. Complete occlusion was demonstrated in 1 additional patient at 1 year after treatment. The authors did not provide details as to whether these patients were initially treated with PED alone or PED with coil embolization. Likewise, Lylyk et al., in the Buenos Aires experience, noted occlusion rates of $56 \%, 93 \%$, and $95 \%$ at 3,6 , and 12 months, respectively, in 53 patients treated for 63 intracranial aneurysms. ${ }^{14}$

In the Pipeline for Uncoilable or Failed Aneurysms (PUFs) trial, complete occlusion of the aneurysm was seen in $79(86.8 \%)$ of the 91 aneurysms treated in the 89 patients who underwent catheter angiography at the 1-year follow- up evaluation. ${ }^{2}$ While the occlusion rate in this trial was lower than in other reported trials, including our series, it is important to note that the PUFs trial was designed to investigate large or giant aneurysms. As such, the mean aneurysm size in this series was larger than in other reported series. Additionally, the PUFs trial was designed to examine the safety and efficacy of the PED as a standalone construct in this subset of aneurysms. The use of adjunctive coil embolization was penalized in their analysis and considered a failure of primary outcome. The authors admit that this may have encouraged the use of multiple PEDs to ensure optimal results.

Szikora et al. described complete occlusion of widenecked intracranial aneurysms in 17 (94\%) of 18 patients at 6 months. ${ }^{22}$ Early in their experience, they would routinely use adjunctive coil embolization (10 of 19 patients) with loose packing (average coil packing density 13.4\%). However, in the latter part of their series, they relied mostly on a strategy of overlapping PEDs. Despite the fact that the uncoiled aneurysms were larger, the occlusion rates between the 2 groups were similar at 6 months (10 of 10 aneurysms treated with PED/coils occluded versus 8 of 9 treated with PED alone). Based upon their findings, the authors state that they reserve adjunctive coil embolization for those aneurysms that are felt to have a higher risk of rupture. Their strategy, however, requires the use of more PEDs in uncoiled aneurysms to increase the neck coverage and improve flow diversion.

In our series, there was no significant difference in the number of PEDs used in either cohort. In fact, due to our findings of increased complication rates with the PED, we have attempted to limit the number of devices used in each case. ${ }^{19}$ On average, we used fewer PEDs with adjunctive coil embolization than with PED alone (Table 1), but this was not a statistically significant difference. Potentially, adjunctive coil embolization may reduce the number of PEDs necessary to achieve a satisfactory result. This difference in practice may account for the difference in our findings.

\section{Aneurysm Characteristics}

The aneurysms requiring re-treatment were significantly larger than those not requiring re-treatment in the PED-alone cohort (Table 2). The 1 patient in the PED/coil cohort requiring re-treatment also had a large aneurysm $(22 \mathrm{~mm})$ of the posterior circulation. Given the larger size, it makes sense intuitively that more PEDs would be required during the treatments (Table 4).

We also noted a statistically significant difference between the treatment groups in the location of the treated aneurysms (Table 1). More posterior circulation aneurysms were treated in the PED-alone cohort than in the $\mathrm{PED} /$ coil cohort. While the reasons for this are unclear, it may reflect a higher tendency to reserve the use of the PED for fusiform aneurysms in the posterior circulation that are less amenable to adjunctive coil embolization or a more conservative approach when using the device in an off-label manner. Despite this difference, all re-treatments involved the anterior circulation in the PED-alone cohort. We are not certain whether size had any role in this finding in relation to aneurysm location. 


\section{Re-Treatments Following PED}

Re-treatments after use of the PED have been described previously. In a series of 101 patients treated with PEDs, Fischer et al. identified 8 patients $(9 \%)$ who required a second treatment with additional PEDs. ${ }^{11}$ These patients were re-treated due to persistent or unchanged aneurysm filling in 7 cases and 1 de novo aneurysm formation in 1 case. The authors did not examine their re-treatments based upon the initial treatment strategy. Our overall retreatment rate $(6.8 \%, 9 / 133)$ is in line with these previously reported findings.

Prior treatments have been suggested as a risk factor for incomplete occlusion following PED use. McAuliffe et al. noted an $85.7 \%$ occlusion rate with PED use in their series of 54 patients treated at 3 Australian centers, the majority of whom were treated with PED alone (49 of 57 cases). ${ }^{15}$ Eliminating patients with prior endovascular treatments from their analysis, however, improved their occlusion rate to $92.5 \%$. They hypothesized that the presence of a previous stent limited the wall apposition of the PED, leading to worse outcomes. Indeed, 3 of the 6 PEDs used in this setting became occluded. Three of the 8 patients in our PED-alone re-treatment cohort had prior treatment. However, these patients experienced aneurysm recurrence after treatment with clip ligation. The 1 patient in the PED/ coil cohort requiring re-treatment had not been previously treated.

Additionally, the decision to re-treat is a highly nuanced one. While some case series have reported an occlusion rate greater than $85 \%-90 \%$ by 6 months to 1 year, those aneurysms that remain only partially occluded represent a management dilemma. ${ }^{2,5,11,14,18,22}$ In our PED-alone cohort, we elected to re-treat incompletely occluded aneurysms at the 6-month time point on average. While waiting an additional 6 months may allow a small percentage of these aneurysms to progress to complete occlusion, this decision exposes the patient to a theoretical risk of aneurysm rupture in the intervening time. It is also possible that a portion of the aneurysms that do not progress to complete occlusion with PED use alone may be successfully treated by combining coil embolization with PED use. Thus, it was our practice to proceed with early re-treatment of incompletely occluded aneurysms rather than continuing to observe these lesions.

Large side branches arising from the neck of the aneurysm may also contribute to inadequate results following PED use. Interestingly, in our series, all PED/alone retreatments not related to device and technical complications (i.e., PED migration/retraction) involved aneurysms of the cavernous ICA where large side branches would not be located (Table 3). This subset of PED-alone re-treatments also represented on-label PED cases that would have likely been amenable to either treatment strategy. Except for the cases previously illustrated, there were no instances of poor PED apposition, endoleaks, and/or inadequate landing zones for the PED.

Device migration/retraction is another well-described phenomenon with flow-diverting stents that we identified in 2 of our patients (Fig. 1), ${ }^{4,6,8,16,19}$ Depending on the extent of movement, the neck of the aneurysm may no longer be covered. In these instances, re-treating the aneurysm would be the prudent option. Chalouhi et al. even suggest that the use of adjunctive coil embolization may prevent a retracted PED from prolapsing into the aneurysm. ${ }^{4}$ Theoretically, the presence of coils may provide enough friction to make PED movement less likely to occur. This hypothesis, however, is unproven.

We have not attempted to analyze our data in terms of cost-efficiency. While there are reports of real and theoretical cost benefits to PED use versus coiling, no similar comparisons have been performed in regard to the addition of coil embolization to PED treatment. ${ }^{4,9}$ Certainly, the addition of coils to a flow-diversion procedure could increase the equipment costs and procedural times. However, this would only hold true if the same number of PEDs would be used with or without coil embolization. ${ }^{4}$ As we have seen in several studies, there may be a tendency to deploy multiple flow diverters when they are used as stand-alone constructs, which would undoubtedly increase equipment costs and procedural times. ${ }^{2,22}$

When considering using coils in conjunction with flow diverters, one should remember that subsequent noninvasive follow-up is limited by increased artifact from the coils. Additionally, if a dense coil mass is placed before deploying the flow diverter, visualization of the flow diverter as it is deployed may be impaired.

\section{Study Limitations}

Shortcomings of this study include the lack of randomization, the single-center experience, and the limited duration of follow-up. As previously mentioned, decisions to proceed with either treatment strategy and/or re-treatments were made by the senior authors according to experience and judgment in these cases. Certainly, this introduces an element of bias in our study.

\section{Conclusions}

While the PED has been a significant addition to the armamentarium of the neuro-interventional surgeon, the optimum strategy for its use has not been clearly elucidated. In our retrospective series, aneurysms treated with adjunctive coil embolization were statistically less likely to require additional treatments despite similar patient and aneurysm characteristics. Additionally, larger aneurysms treated with a strategy of PED alone were more likely to require re-treatment than smaller aneurysms within the same cohort. These findings may serve as a basis for further research into the advantages and disadvantages of each treatment strategy which will be necessary before any definitive recommendations can be made.

\section{Acknowledgments}

We would like to thank Kristina Chapple, $\mathrm{PhD}$, for her help with statistical analysis.

\section{References}

1. Albuquerque FC, Park MS, Abla AA, Crowley RW, Ducruet AF, McDougall CG: A reappraisal of the Pipeline embolization device for the treatment of posterior circulation aneurysms. J Neurointerv Surg 7:641-645, 2015

2. Becske T, Kallmes DF, Saatci I, McDougall CG, Szikora I, Lanzino G, et al: Pipeline for uncoilable or failed aneurysms: 
results from a multicenter clinical trial. Radiology 267:858868, 2013

3. Brinjikji W, Cloft HJ, Fiorella D, Lanzino G, Kallmes DF: Estimating the proportion of intracranial aneurysms likely to be amenable to treatment with the pipeline embolization device. J Neurointerv Surg 5:45-48, 2013

4. Chalouhi N, Jabbour P, Tjoumakaris S, Starke RM, Dumont AS, Liu H, et al: Treatment of large and giant intracranial aneurysms: cost comparison of flow diversion and traditional embolization strategies. World Neurosurg 82:696-701, 2014

5. Chalouhi N, Tjoumakaris S, Phillips JL, Starke RM, Hasan $\mathrm{D}, \mathrm{Wu} \mathrm{C}$, et al: A single pipeline embolization device is sufficient for treatment of intracranial aneurysms. AJNR Am J Neuroradiol 35:1562-1566, 2014

6. Chalouhi N, Tjoumakaris SI, Gonzalez LF, Hasan D, Pema PJ, Gould G, et al: Spontaneous delayed migration/shortening of the pipeline embolization device: report of 5 cases. AJNR Am J Neuroradiol 34:2326-2330, 2013

7. Chalouhi N, Zanaty M, Whiting A, Yang S, Tjoumakaris SI, Hasan DM, et al: Safety and efficacy of the pipeline embolization device in 100 small intracranial aneurysms. J Neurosurg 122:1498-1502, 2015

8. Cohen JE, Gomori JM, Moscovici S, Leker RR, Itshayek E: Delayed complications after flow-diverter stenting: reactive in-stent stenosis and creeping stents. J Clin Neurosci 21:1116-1122, 2014

9. Colby GP, Lin LM, Paul AR, Huang J, Tamargo RJ, Coon AL: Cost comparison of endovascular treatment of anterior circulation aneurysms with the pipeline embolization device and stent-assisted coiling. Neurosurgery 71:944-950, 2012

10. Fiorella D, Woo HH, Albuquerque FC, Nelson PK: Definitive reconstruction of circumferential, fusiform intracranial aneurysms with the pipeline embolization device. Neurosurgery 62:1115-1121, 2008

11. Fischer S, Vajda Z, Aguilar Perez M, Schmid E, Hopf N, Bäzner H, et al: Pipeline embolization device (PED) for neurovascular reconstruction: initial experience in the treatment of 101 intracranial aneurysms and dissections. Neuroradiology 54:369-382, 2012

12. Kan P, Siddiqui AH, Veznedaroglu E, Liebman KM, Binning MJ, Dumont TM, et al: Early postmarket results after treatment of intracranial aneurysms with the pipeline embolization device: a U.S. multicenter experience. Neurosurgery 71:1080-1088, 2012

13. Kulcsár Z, Houdart E, Bonafé A, Parker G, Millar J, Goddard AJ, et al: Intra-aneurysmal thrombosis as a possible cause of delayed aneurysm rupture after flow-diversion treatment. AJNR Am J Neuroradiol 32:20-25, 2011

14. Lylyk P, Miranda C, Ceratto R, Ferrario A, Scrivano E, Luna HR, et al: Curative endovascular reconstruction of cerebral aneurysms with the pipeline embolization device: the Buenos Aires experience. Neurosurgery 64:632-643, 2009

15. McAuliffe W, Wycoco V, Rice H, Phatouros C, Singh TJ, Wenderoth J: Immediate and midterm results following treatment of unruptured intracranial aneurysms with the pipeline embolization device. AJNR Am J Neuroradiol 33:164-170, 2012

16. McTaggart RA, Santarelli JG, Marcellus ML, Steinberg GK, Dodd RL, Do HM, et al: Delayed retraction of the pipeline embolization device and corking failure: pitfalls of pipeline embolization device placement in the setting of a ruptured aneurysm. Neurosurgery 72 (2 Suppl Operative):onsE245onsE251, 2013
17. Moon K, Albuquerque F, Ducruet AF, Crowley RW, McDougall CG: Resolution of cranial neuropathies following treatment of intracranial aneurysms with the pipeline embolization device. J Neurosurg 121:1085-1092, 2014

18. Nelson PK, Lylyk P, Szikora I, Wetzel SG, Wanke I, Fiorella D: The pipeline embolization device for the intracranial treatment of aneurysms trial. AJNR Am J Neuroradiol 32:34-40, 2011

19. Park MS, Albuquerque FC, Nanaszko M, Sanborn MR, Moon $\mathrm{K}$, Abla AA, et al: Critical assessment of complications associated with use of the Pipeline Embolization Device. J Neurointerv Surg 7:652-659, 2015

20. Siddiqui AH, Abla AA, Kan P, Dumont TM, Jahshan S, Britz $\mathrm{GW}$, et al: Panacea or problem: flow diverters in the treatment of symptomatic large or giant fusiform vertebrobasilar aneurysms. J Neurosurg 116:1258-1266, 2012

21. Siddiqui AH, Kan P, Abla AA, Hopkins LN, Levy EI: Complications after treatment with pipeline embolization for giant distal intracranial aneurysms with or without coil embolization. Neurosurgery 71:E509-E513, 2012

22. Szikora I, Berentei Z, Kulcsar Z, Marosfoi M, Vajda ZS, Lee $\mathrm{W}$, et al: Treatment of intracranial aneurysms by functional reconstruction of the parent artery: the Budapest experience with the pipeline embolization device. AJNR Am J Neuroradiol 31:1139-1147, 2010

23. Turowski B, Macht S, Kulcsár Z, Hänggi D, Stummer W: Early fatal hemorrhage after endovascular cerebral aneurysm treatment with a flow diverter (SILK-Stent): do we need to rethink our concepts? Neuroradiology 53:37-41, 2011

24. Zanaty M, Chalouhi N, Starke RM, Barros G, Saigh MP, Schwartz EW, et al: Flow diversion versus conventional treatment for carotid cavernous aneurysms. Stroke 45:2656-2661, 2014

\section{Disclosures}

Cameron G. McDougall reports that he is a consultant for Covidien (owner of ev3 Neurovascular, the manufacturer of the Pipeline Embolization Device) and Microvention (manufacturer of a competing device). The other authors report that they have no personal, financial, or institutional interest in any of the devices described in this article.

\section{Author Contributions}

Conception and design: McDougall, Park, Albuquerque. Acquisition of data: Park, Nanaszko, Sanborn, Moon. Analysis and interpretation of data: Park, Nanaszko, Sanborn, Moon. Drafting the article: McDougall, Park, Albuquerque. Critically revising the article: McDougall, Park, Albuquerque. Reviewed submitted version of manuscript: McDougall, Park. Statistical analysis: Park, Nanaszko, Sanborn, Moon. Administrative/technical/material support: Park, Nanaszko, Sanborn, Moon. Study supervision: McDougall, Albuquerque.

\section{Correspondence}

Cameron G. McDougall, c/o Neuroscience Publications, Barrow Neurological Institute, St. Joseph's Hospital and Medical Center, 350 W. Thomas Rd., Phoenix, AZ 85013.email: neuropub@ dignityhealth.org. 